Development of novel UV emitting single crystalline film scintillators

This article has been downloaded from IOPscience. Please scroll down to see the full text article.

2011 J. Phys.: Conf. Ser. 289012029

(http://iopscience.iop.org/1742-6596/289/1/012029)

View the table of contents for this issue, or go to the journal homepage for more

Download details:

IP Address: 131.169.39.151

The article was downloaded on 16/01/2012 at 15:49

Please note that terms and conditions apply. 


\title{
Development of novel UV emitting single crystalline film scintillators
}

\author{
Yu Zorenko ${ }^{1}, \mathbf{V}$ Gorbenko ${ }^{1}$, V Savchyn ${ }^{1}$, T Voznyak ${ }^{1}$, M Nikl $^{2}$, J A Mares $^{2}$, T Martin $^{3}$, \\ P-A Douissard ${ }^{3}$ \\ ${ }^{1}$ Laboratory of Opoelectronic Materials (LOM), Electronics Department of Ivan Franko \\ National University of Lviv, 79017 Lviv, Ukraine \\ ${ }^{2}$ Institute of Physics of ASCR, 16253 Prague, Czech Republik \\ ${ }^{3}$ ESRF, Instrument Support Group, 6 rue Jules Horoeitz, 38043 Grenoble, France
}

\section{E-mail: zorenko@electronics.wups.lviv.ua}

\begin{abstract}
The work is dedicated to development of new types of UV -emitting scintillators based on single crystalline films $(S C F)$ of aluminimum perovskites and garnets grown by the liquid phase epitaxy (LPE) method. The development of the following three types of UV SCF scintillators is considered in this work: i) Ce-doped $S C F$ of Y-Lu-Al-perovskites with $\mathrm{Ce}^{3+}$ emission in the 360$370 \mathrm{~nm}$ range with a decay time of 16-17 ns; ii) Pr-doped $S C F$ of Y-Lu-Al garnets with $\operatorname{Pr}^{3+}$ emission in the 300-400 nm range with a decay time of 13-17 ns; iii) $\mathrm{La}^{3+}$ and $\mathrm{Sc}^{3+}$ doped $S C F$ of $\mathrm{Y}$-Lu-Al-garnets, emitting in the $290-400 \mathrm{~nm}$ range due to formation of the $\mathrm{La}_{\mathrm{Y}, \mathrm{Lu}}, \mathrm{Sc}_{\mathrm{Y}, \mathrm{Lu}}$ and $\mathrm{Sc}_{\mathrm{Al}}$ centers with decay time of 250-575 ns. The results of testing the several novel UV-emitting SCFs scintillators for visualization of X-ray images at ESFR are presented. It is shown that the UV emission of the LuAG:Sc, LuAG:La and LuAG:Pr SCFs is efficient enough for conversion of Xray to the UV light and that these scintillators can be used for improvement of the resolution of imaging detectors in synchrotron radiation applications.
\end{abstract}

\section{Introduction}

During the last 30 years the liquid phase epitaxy (LPE) shows oneself as a beneficial method for the development of new types of luminescent materials based on single crystalline films (SCF) of oxide compounds (garnets, perovskites, sapphire, silicates, tungstates)[1-3]. The fields of application of such $S C F$ are now extended to $\alpha$ - and $\beta$ - scintillators, screens for visualization of X-ray images, cathodoluminescent screens as light sources for scanning optical microscopes, laser media and luminescent converters of LED radiation [1-9].

In several previous works $[2,4,10,11]$ we have demonstrated the creation by LPE method of the $S C F$ scintillators based on $\mathrm{Y}_{3} \mathrm{Al}_{5} \mathrm{O}_{12}$ : $\mathrm{Ce}$ (YAG:Ce) and $\mathrm{Lu}_{3} \mathrm{Al}_{5} \mathrm{O}_{12}$ (LuAG:Ce) garnets emitting in visible (450$750 \mathrm{~nm}$ ) range with a decay time of 70 and $50 \mathrm{~ns}$ respectively. We have also shown [12-16] that these $S C F$ scintillators in comparison with bulk single crystal (SC) analogues are characterized by faster $\mathrm{Ce}^{3+}$ emission decay under high energy excitation, substantially less (by 4.5-8 times) content of slow emission components and higher energy resolution due to the absence in them of $\mathrm{Y}_{\mathrm{Al}}$ and $\mathrm{Lu}_{\mathrm{Al}}$ antisite defects (ADs) and low concentration of vacancies as luminescence and trapping centers.

In this work, we focus on the development of emitting in the UV range $S C F$ scintillators based on garnet and perovskites compounds. The reasons for the development of such scintillators are as follows: 
1.Shift of the emission spectra of $S C F$ scintillators into the UV range with respect to recently developed $S C F$ s of LuAG:Ce anf YAG:Ce garnets, emitting in visible range, in principle can result in the faster emission decay, larger light yield (LY) and higher energy resolution [4,15]. Specifically, we plan to extend the class of novel SCF scintillators which effectively emit in UV ranges, on Ce-doped perovskites (YAP:Ce and LuAP:Ce) and $\mathrm{Pr}^{3+}$-doped garnets (LuAG:Pr and YAG:Pr).

2. Microimaging techniques with synchrotron or X-ray radiation for applications in microtomography and industry [5-7] demands fast, on-lne X-ray image detectors with spatial resolution in the $\mu \mathrm{m}$ or sub- $\mu \mathrm{m}$ range. For this task, a X-ray image detectors based on YAG:Ce SCF, microscope optics, a low-noise CCD camera, operated at X-ray energies of $10-50 \mathrm{keV}$ have been recently developed $[5,6]$. The spatial resolution of X-ray images of $0.8 \mu \mathrm{m} \mathrm{FWHM} \mathrm{is} \mathrm{achieved} \mathrm{.} \mathrm{Future} \mathrm{increase} \mathrm{of} \mathrm{the} \mathrm{spatial} \mathrm{resolution} \mathrm{of} \mathrm{detector}$ requires creation of the $S C F$ scintillating screens emitting the UV light. Registration in the UV range could increase the spatial resolution of a detector according to the formula: $0.61 * \lambda / \mathrm{NA}$, where $\lambda$ is the emission wavelength, NA is the numerical aperture of the optics.

In this work we have studied the scintillation properties of several types of UV emitting SCF scintillators prepared by LPE method. For visualization of X-ray images in the UV light we also tested at $E_{S R F}^{3}$ the novel $S C F$ scintillators based on LuAG garnet and LuAP perovskites compounds which have significantly higher density $\left(\rho=6.67\right.$ and $\left.8.34 \mathrm{~g} / \mathrm{cm}^{3}\right)$ and effective atomic number $\left(Z_{\text {eff }}=59\right.$ and 62$)$ $[6,7,10,11]$ as compared to commonly used YAG $\left(\rho=4.6 \mathrm{~g} / \mathrm{cm}^{3}, Z_{\text {eff }}=29\right)[4,5]$. As mentioned above, for creation of the intense UV light, the $\mathrm{Pr}^{3+}$ as well as La3 + and $\mathrm{Sc}^{3+}$ ions can be used as activators in LuAG $S C F$ and $\mathrm{Ce}^{3+}$ ions in LuAP $S C F$ respectively.

\section{Growth of $\boldsymbol{S C F}$ scintillators and experimental technique}

The series of Pr, La and Sc-doped YAG and LuAG and Ce-doped YAP and LuAP SCF scintillators were grown in LOM Lviv University by the LPE methods onto YAG and YAP substrates, respectively, with super-cooled melt - solution (MS) based on the $\mathrm{PbO}-\mathrm{B}_{2} \mathrm{O}_{3}$ flux at relatively low temperatures (950-1100 $\left.{ }^{\circ} \mathrm{C}\right)$ as compared to Czochralski - grown $S C\left(\sim 2000^{\circ} \mathrm{C}\right)$. The thickness of the $S C F$ scintillators was varied in the 4.8-45 $\mu \mathrm{m}$ range. It is important to note, that we did not use any additional doping to reduce the significant differences in the lattice constants of the LuAG- and LuAP- based SCF and the YAG and YAP substrates which are equal to about 1.0 and $1.4 \%$ respectively [18-20].

The lower growth temperature of $S C F$ results in absence of $\mathrm{Y}_{\mathrm{AL}}$ and $\mathrm{Lu}_{\mathrm{AL}} A D s$ and decrease of concentration of other type of defects in $S C F$ in comparison with bulk $S C$ analogues [13,17]. On the other hand, flux components can be introduced in the $S C F$ that might have detrimental influence on their emission and scintillation properties [21-24]. Usually, the $S C F$ s prepared from the $\mathrm{PbO}$-based flux, can contain lead ions preferably in the $\mathrm{Pb}^{2+}$ charge state. Since the $\mathrm{PbO}$ - based melt dissolves the Pt-crucible, $\mathrm{Pt}^{4+}$ ions can also be introduced in the garnet or perovskites lattices. As a consequence, various locally non- compensated lattice defects can be created, which may result in the decrease of the scintillation efficiency and light yield of $S C F$ scintillators (LY) [2,4,20,24].

Therefore, the LY of Pr-, La- and Sc-doped YAG and LuAG SCF and Ce-doped YAP and LuAP SCF scintillators in the UV range can strongly depend on the concentration in them of activators as well as $\mathrm{Pb}^{2+}$ and $\mathrm{Pt}^{4+}$ dopants. In principle, the suitable LY of the mentioned $S C F$ can be achieved by means of optimization of the activator content in MS [2,10,21,22,24]. Specifically, due to significant difference in the segregation coefficient of $\mathrm{La}^{3+}, \mathrm{Sc}^{3+}$ and $\mathrm{Pr}^{3+}$ ions at the crystallization of YAG and LuAG SCF onto YAG substrates $[20,21]$ and $\mathrm{Ce}^{3+}$ ions at crystallization of YAP and LuAP SCF onto YAP substrates [20,24], the concentrations of $\mathrm{Sc}_{2} \mathrm{O}_{3}, \mathrm{La}_{2} \mathrm{O}_{3}, \mathrm{Pr}_{2} \mathrm{O}_{3}$ and $\mathrm{CeO}_{2}$ activated oxides in $\mathrm{MS}$ was varied in the 4.6$6.7,1-8.2,3.1-8.6$ and $2-20$ mole $\%$ ranges, respectively. At the same time, the concentration of different impurities in the $S C F$ depends not only on the content of activated oxides in MS, but is also strongly influenced by the $S C F$ growth temperature. Of the most importance is that the concentrations of dopants as well as $\mathrm{Pb}^{2+}$ and $\mathrm{Pt}^{4+}$ flux impurities increase with decreasing the growth temperature and vice versa $[21,22,24]$. For these reasons we have used relatively high growth temperatures above $950^{\circ} \mathrm{C}$ for $S C F$ preparation. 
The content of different dopants in SCF was determined using JEOL JXA-8612 MX electron microscope and presented in table 1 for different series of $S C F$ scintillators.

Table1. Relative LY of the best samples in series of UV-emitting SCF scintillators in comparison with standard bulk $S C$ analogues under excitation by $\alpha$-particles of $\mathrm{Pu}^{239}$ sources $(5.15 \mathrm{MeV})$. The concentration of $\mathrm{Y}_{\mathrm{Al}}$ and $\mathrm{Lu}_{\mathrm{Al}} A D s$ estimated by XRD analysis is presented for undoped YAG and LuAG SC

\begin{tabular}{|c|c|c|c|c|c|}
\hline Dopant & Scintillators & $\begin{array}{l}\text { Activator } \\
\text { content, } \\
\text { at. } \%\end{array}$ & $\begin{array}{c}\text { Maximum } \\
\text { of emission } \\
\text { band, nm }\end{array}$ & $\begin{array}{l}\text { Decay time of } \\
\text { main emission } \\
\text { component, ns }\end{array}$ & $\begin{array}{c}\mathbf{L Y}, \% \\
\operatorname{Am}^{241}(3 \mu \mathrm{s}) / \\
\operatorname{Pu}^{239}(0.5 \mu \mathrm{s})\end{array}$ \\
\hline \multirow[t]{2}{*}{$\mathbf{C e}$} & 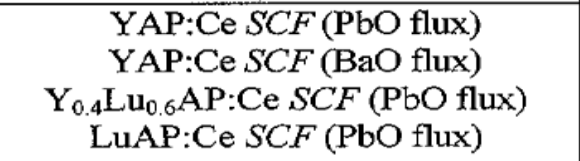 & \begin{tabular}{c|}
0.08 \\
0.053 \\
$\sim 0.04$ \\
0.013
\end{tabular} & $\begin{array}{l}366 \\
373 \\
363 \\
358\end{array}$ & \begin{tabular}{l|}
13.1 \\
16.1 \\
16.0 \\
16.9
\end{tabular} & $\begin{array}{c}36.1 / 25.5 \\
-/ 23.8 \\
-/ 10.2 \\
-/ 7.65\end{array}$ \\
\hline & $\begin{array}{c}\text { YAP:Ce } S C \\
\mathrm{Lu}_{0.3} \mathrm{Y}_{0.7} \mathrm{AG}: \mathrm{Ce} S C\end{array}$ & $\begin{array}{l}\sim 0.1 \\
\sim 0.1 \\
\end{array}$ & $\begin{array}{l}366 \\
375 \\
\end{array}$ & $\begin{array}{l}16.2 \\
17.1 \\
\end{array}$ & $\begin{array}{c}100 / 100 \\
83.2 / 56.3 \\
\end{array}$ \\
\hline \multirow[b]{2}{*}{$\mathbf{P r}$} & $\begin{array}{l}\text { YAG:Pr } S C F \\
\text { LuAG:Pr } S C F\end{array}$ & $\begin{array}{c}0.085 \\
0.66\end{array}$ & $\begin{array}{l}323 \\
305\end{array}$ & $\begin{array}{l}13 \\
17\end{array}$ & $\begin{array}{l}33.7 / 21.6 \\
29.8 / 24.9\end{array}$ \\
\hline & $\begin{array}{l}\text { YAG:Pr } S C \\
\text { LuAG:Pr } S C\end{array}$ & $\begin{array}{l}0.19 \\
0.31 \\
\end{array}$ & $\begin{array}{l}327 \\
308 \\
\end{array}$ & $\begin{array}{l}17.6 \\
18.6 \\
\end{array}$ & $\begin{array}{l}75.4 / 60.8 \\
59.3 / 55.6 \\
\end{array}$ \\
\hline \multirow[t]{3}{*}{ La } & $\begin{array}{c}\text { YAG:La } S C F \\
\mathrm{Lu}_{2.74} \mathrm{Y}_{0.25} \mathrm{Al}_{5} \mathrm{O}_{12}: \mathrm{La} S C F\end{array}$ & $\begin{array}{c}0.045 \\
0.04\end{array}$ & $\begin{array}{l}297 \\
282\end{array}$ & 170 & $\begin{array}{c}13.6 / 6.9 \\
15.9 / 11.0\end{array}$ \\
\hline & YAG:La SC & 0.085 & 298 & 575 & $-/ 21.0$ \\
\hline & $\begin{array}{l}\text { undoped YAG } S C \\
\text { undoped LuAG } S C\end{array}$ & $\begin{array}{c}0.19^{*} \\
0.575^{*}\end{array}$ & $\begin{array}{l}292 ; 332 \\
296 ; 334 \\
\end{array}$ & $\begin{array}{l}350 ; 1490 \\
440,3020\end{array}$ & $\begin{array}{l}19.8 / 10.9 \\
-/ 18.8 \\
\end{array}$ \\
\hline \multirow[t]{2}{*}{ Sc } & $\begin{array}{c}\mathrm{Y}_{2.96} \mathrm{Sc}_{0.475} \mathrm{Al}_{4.555} \mathrm{O}_{12} S C F \\
\mathrm{Y}_{2.84} \mathrm{Lu}_{0.14} \mathrm{Sc}_{0.37} \mathrm{Al}_{4.65} \mathrm{O}_{12} S C F \\
\mathrm{Y}_{2.76} \mathrm{Lu}_{0.18} \mathrm{Sc}_{0.715} \mathrm{Ga}_{0.095} \mathrm{Al}_{4.25} \mathrm{O}_{12} S C F \\
\mathrm{Lu}_{2.67} \mathrm{Sc}_{0.585} \mathrm{Al}_{4.745} \mathrm{O}_{12} S C F\end{array}$ & $\begin{array}{l}2.38 \\
1.85 \\
3.60 \\
2.93\end{array}$ & $\begin{array}{l}322 \\
314 \\
330 \\
312\end{array}$ & $\begin{aligned} & \sim 750 \\
& \sim 650 \\
& \sim 800 \\
& 245 ; 390\end{aligned}$ & $\begin{array}{l}38.7 / 26.7 \\
57.4 / 48.2 \\
28.0 / 17.8 \\
27.6 / 21.8\end{array}$ \\
\hline & $\begin{array}{c}\mathrm{Y}_{2.995} \mathrm{Sc}_{0.077} \mathrm{Al}_{4.864} \mathrm{O}_{12} S C \\
\mathbf{L u}_{2.773} \mathrm{Sc}_{0.022} \mathrm{Al}_{5.205} \mathrm{O}_{12} S C\end{array}$ & $\begin{array}{l}0.39 \\
0.11\end{array}$ & $\begin{array}{l}314 \\
290\end{array}$ & $\begin{array}{r}\sim 580 \\
1330 \\
\end{array}$ & $\begin{array}{l}69.3 / 45.9 \\
31.4 / 21.8\end{array}$ \\
\hline
\end{tabular}

For estimation of the scintillation efficiency in the UV range of the developed $S C F$ scintillators with garnet and perovskites structure the relative LY measurements of all corresponding series $S C F$ samples were performed in comparison with standard samples of YAG:Pr, LuAG:Pr, YAG:La, YAG:Sc, LuAG:Sc,YAP:Ce and $\mathrm{Lu}_{0.3} \mathrm{Y}_{0.7} \mathrm{AG}$ :Ce bulk $S C$ scintillators under excitation by $\alpha$-particles of $\mathrm{Pu}^{239}(5.15$ $\mathrm{MeV})$ and $\mathrm{Am}^{241}(5.4857 \mathrm{MeV})$ sources with a penetration length in studied materials of about 10-12 $\mu \mathrm{m}$. For LY measurements we used the detectors based on FEU-110 and hybrid DEP PPO 475B PMT types which have the maximum sensitivity in the 250-375 and 200-400 $\mathrm{nm}$ ranges and mulitichannel single photon counting system working within a time interval of 0.5 and $3 \mu \mathrm{s}$, respectively. The results of YL measurements are presented in Table 1.

For the correct characterization of the luminescent properties of the tested series of UV-emitting SCF we used measurements of their cathodoluminescence (CL) spectra under pulsed e-beam excitation ( a pulse duration of $2 \mu \mathrm{s}$ and a frequency of $30-3 \mathrm{~Hz}$ ) with energy of electrons of $9 \mathrm{keV}$ and a beam current of $100 \mu \mathrm{A}$. Emission spectra were corrected for the spectral dependence of the detection part consisting of DMR-4 monochromator and FEU-106 photomultiplier (PMT).

The decay kinetics of luminescence were measured at $300 \mathrm{~K}$ in the time interval $0-200 \mathrm{~ns}$ under excitation $S C F$ and $S C$ scintillators by synchrotron radiation (SR) with a pulse duration of $0.126 \mathrm{~ns}$ at Superlumi experimental station in HASYLAB,DESY. 


\section{Luminescence spectra and $L Y$ of $S C F$ scintillators}

\subsection{Ce-doped perovskites}

The CL spectra of YAP:Ce and LuAP:Ce SCF (Fig.1, curve 1 and 2) present intensive emission band in the UV (320-450 nm) range related to the $5 \mathrm{~d}^{1} \rightarrow 4 \mathrm{f}\left({ }^{2} \mathrm{~F}_{5 / 2,7 / 2}\right)$ transitions of $\mathrm{Ce}^{3+}$ ions $[19,20,24]$. It is important to note that the short-wavelength part of the $\mathrm{Ce}^{3+}$ emission spectra in YAP:Ce and LuAP:Ce $S C F$, growth from $\mathrm{PbO}$ - based flux, can be strongly distorted by the UV emission band of $\mathrm{Pb}^{2+}$ ions peaked at $340 \mathrm{~nm}$ [25] (Fig.1). This caused a notable short-wavelength shift of the emission spectrum of YAP:Ce $S C F$, grown from the PbO-based flux, with respect to the luminescence spectrum of the same $S C F$, grown from the lead-free flux. Other low-intensity complex emission band in YAP:C and LuAP:Ce $S C F$, related to the luminescence of excitons localized around of $\mathrm{Pb}^{2+}$ ions, is located in the visible range with maximum approximately at $590 \mathrm{~nm}$ (Fig.1).

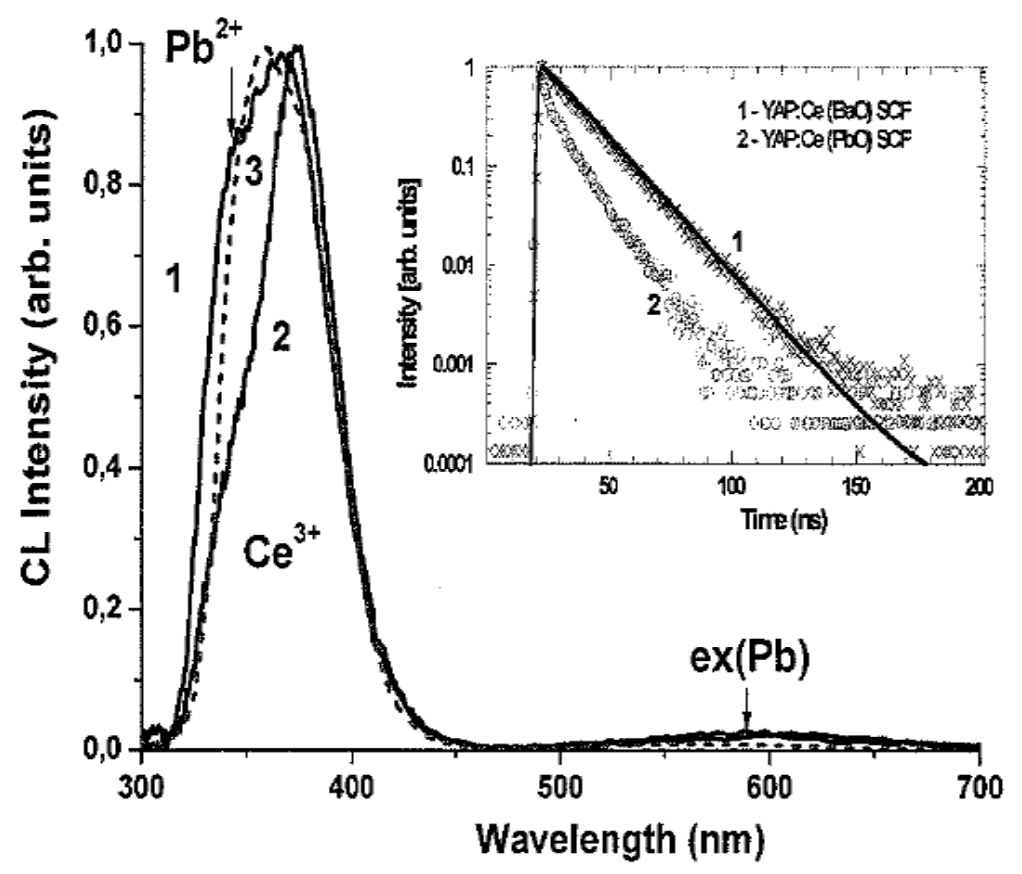

Figure 1. Normalized CL spectra of YAP:Ce $(1,2)$ and LuAP:Ce (3) SCF; insert normalized luminescence decay kinetics of YAP:Ce $S C F$, grown from the $\mathrm{BaO}-(1)$ and PbO-based (2) flux under excitation in $\mathrm{Ce}^{3+}$ absorption band at $300 \mathrm{~nm} ; \mathrm{T}=300 \mathrm{~K}$

As can be seen from Table 1, the LY of YAP:Ce and especially of LuAP:Ce $S C F$ scintillators, grown even at the optimal $\mathrm{CeO}_{2}$ content in the MS of 10-20 mol\%, is significantly lower (by 3.9 anf 7.6 times, respectively) then that of their YAP:Ce and (Y-Lu)AP:Ce $S C$ analogues. The main reason for such low LY of YAP:Ce and LuAP:Ce $S C F$ scintillators is the large incorporation of $\mathrm{Pb}^{2+}$ ions in $S C F$ of perovskites in comparison with SCF of garnets [23] due to larger volume of cub-octahedral position in perovskites lattice with respect to the dodecahedral position of garnet lattice, where $\mathrm{Pb}^{2+}$ ions are localized. We also note that the LY of (Y-Lu)AP:Ce $S C F$ systematically decrease with increasing the Lu content up to a value of $7.65 \%$ for LuAP:Ce $S C F$ as compared to that of YAP:Ce $S C$. This effect can be explained by the large incorporation of $\mathrm{Pb}^{2+}$ ions in LuAP-based $S C F$ with respect to YAP $S C F$ due to preferable $\mathrm{Lu}-\mathrm{Pb}$ pair incorporation in comparison with $\mathrm{Y}-\mathrm{Pb}$ pair in the case of $S C F$ crystallization of both types of perovskites onto YAP substrates [20].

We have also observed the visible acceleration of decay kinetics of the $\mathrm{Ce}^{3+}$ luminescence in YAP:Ce $S C F$, grown from PbO-based flux (Fig.1, insert, curve 2). The decay curve for this YAP:Ce $S C F$ is strongly non-exponential and can be quantitatively characterized by an average decay time of $13.1 \mathrm{~ns}$ 
(Table 1). Such acceleration of the decay kinetics of the $\mathrm{Ce}^{3+}$ luminescence in YAP:Ce $S C F$ scintillators grown from $\mathrm{PbO}$-based flux, can be caused by the energy transfer from $\mathrm{Ce}^{3+}$ ions to $\mathrm{Pb}^{2+}$ related centers, which have the excitation bands in the 350-370 $\mathrm{nm}$ range, well overlapped with $\mathrm{Ce}^{3+}$ emission band [26]. In opposite to this $S C F$, the decay kinetics of the $\mathrm{Ce}^{3+}$ luminescence in YAP:Ce $S C F$, grown from $\mathrm{BaO}-$ based flux, is strongly exponential (insert of Fig.1, curve 2) with a decay time of $16 \mathrm{~ns}$, which is very close to the decay time of the $\mathrm{Ce}^{3+}$ emission in YAP:Ce $S C$ (Table 1).

From calculation of the integral of normalized decay curves for YAP:Ce $S C F$, grown from the $\mathrm{BaO}-$ and $\mathrm{PbO}$-based fluxes, which is equal to 100 and $46 \%$, respectively, we can conclude that in the last $S C F$ scintillators the losses of more than $50 \%$ excitation energy take place due to energy transfer away from $\mathrm{Ce}^{3+} 5 \mathrm{~d}^{1}$ excited state to $\mathrm{Pb}^{2+}$ - based centers [24]. Such huge loss can partly explain such low LY of YAP:Ce and LuAG:Ce $S C F$ scintillators, grown from $\mathrm{PbO}$ - based flux (Table 1).

\section{$3.2 \mathrm{Pr}^{3+}$ doped garnets}

The CL spectra of YAG:Pr and LuAG:Pr show intensive and fast emission in the 290-450 nm range with main maxima at 305 and $322 \mathrm{~nm}$, respectively, caused by the $5 \mathrm{~d}^{1} 4 \mathrm{f}^{1} \rightarrow 4 \mathrm{f}^{2}\left({ }^{3} \mathrm{H}_{4},{ }^{3} \mathrm{H}_{5},{ }^{3} \mathrm{H}_{6},{ }^{3} \mathrm{~F}_{3(4)}\right)$ transition of $\operatorname{Pr}^{3+}$ ions. The sharp-line emission bands peaked at 487, 501 and $563 \mathrm{~nm}$ as $609-620,638$ and $663 \mathrm{~nm}$ in the visible range, are related to the transition from the ${ }^{3} \mathrm{P}_{0}$ and ${ }^{1} \mathrm{D}_{2}$ levels of the $4 \mathrm{f}^{2}$ shell to the ${ }^{3} \mathrm{H}_{6,5,4}$ levels of the ground state of $\operatorname{Pr}^{3+}$ ions (Fig.2,curve 2). The content of slow visible emission is significantly lower in LuAG:Pr $S C F$ than in YAG:Pr $S C F$ (Fig.2).

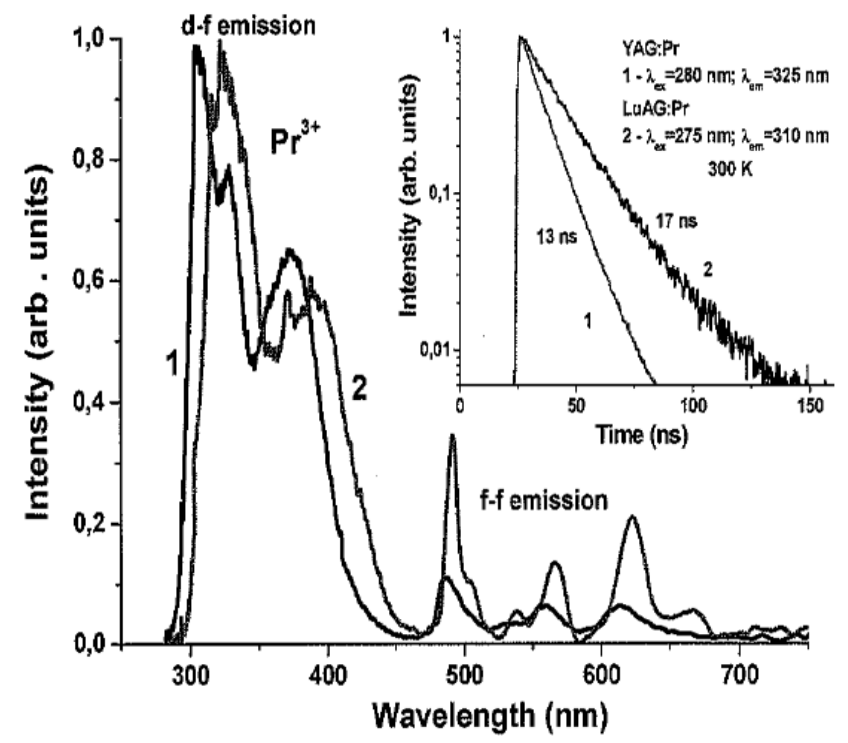

Figure 2. CL spectra and decay kinetics (insert) of $\operatorname{Pr}^{3+}$ luminescence in YAG:Pr (1) and LuAG:Ce (2) $S C F$ at 300K

As can be seen from Table 1, the LY of YAG: Pr and LuAG:Pr SCF scintillators is significantly lower (by 2.2-2.8 times) then that of their $S C$ analogues. This result contradicts with the results of our previous investigations of the LY of Ce-doped YAG and LuAG SCF scintillatores, emitting in the visible (515-530 $\mathrm{nm}$ ) range, with their SC analogues [13].Specifically, for these compounds the comparable LY of SCF and $S C$ scintillators occurs [13]. Taking into account the absence of $\mathrm{Y}_{\mathrm{Al}}$ and $\mathrm{Lu}_{\mathrm{Al}} A D$ and low concentration of vacancy - type defects in YAG and LuAG SCF $[13,14]$, the main reason for lower LY of the $\operatorname{Pr}^{3+}$ - doped $S C F$ scintillatores in comparison with $S C$ of these oxides is the strong quenching influence of $\mathrm{Pb}^{2+}$ flux related impurity. Thus, based on the results presented in Table 1, we can conclude that significantly larger influence of $\mathrm{Pb}^{2+}$ flux dopant on the UV luminescence of $\operatorname{Pr}^{3+}$ ions takes place in YAG:Pr and LuAG:Pr $S C F$ in comparison with the influence of this dopant on the $\mathrm{Ce}^{3+}$ luminescence $\mathrm{n}$ the visible range in Ce- 
doped $S C F$ of these garnets $[13,23]$. The mechanism of $\mathrm{Pb}^{2+} \rightarrow \mathrm{Pr}^{3+}$ energy transfer is considered in detail in [26].

\subsection{La doped garnets}

The CL spectra of YAG:La SC, YAG:La and LuAG:La SCF are shown in Fig.3a. The intensive complex emission bands in the $250-450 \mathrm{~nm}$ range are caused by $\mathrm{La}^{3+}$ isoelectonic impurities. Namely, these bands in YAG:La and LuAG:La SCF presents superposition of two close-lying bands peaked at 298, $305 \mathrm{~nm}$ and $267,282 \mathrm{~nm}$ (Fig.3a,curves 2 and 3 respectively). The short-wavelength bands are related to the luminescence of exciton localized around $\mathrm{La}_{\mathrm{La}, \mathrm{Y}}$ centers $\left(\mathrm{La}^{3+}\right.$ ions in the dodecahedral sites of $\mathrm{Y}^{3+}$ or $\mathrm{Lu}^{3+}$ cations), when the long-wavelength bands are caused by the recombination luminescence of $\mathrm{La}_{\mathrm{Y}}$ and $\mathrm{La}_{\mathrm{Lu}}$ centers. In YAG:La and LuAG:La SCFs, grown from PbO-based flux, the long-wavelength wngs of complex UV emission bands, caused by La dopant, are also overlapped with the UV emission band of $\mathrm{Pb} 2+$ ions peaked at 350-360 $\mathrm{nm}$ [23] (Fig.3a, curve 2 and 3). It is worth to note that the nature of the emission centers formed by $\mathrm{La}^{3+}$ dopant in YAG and LuAG host is similar in the whole to the nature of the centers responsible for the relatively intensive intrinsic UV luminescence of YAG and LuAG bulk SCs (Fig.3 b, curves 1 and 2, respectively). Specifically, this band in YAG and LuAG SCs presents superposition of the luminescence of excitation localized around $\mathrm{Y}_{\mathrm{Al}}$ and $\mathrm{Lu}_{\mathrm{Al}} A D s\left(\mathrm{Y}^{3+}\right.$ and $\mathrm{Lu}^{3+}$ cations in the octahedral sites of $\mathrm{Al}^{3+}$ cations) in the band peaked at 292 and $296 \mathrm{~nm}$ and the recombination luminescence of $\mathrm{Y}_{\mathrm{Al}}$ and $\mathrm{Lu}_{\mathrm{Al}} A D s$ in the bands peaked at 332 and $334 \mathrm{~nm}$, respectively [13].

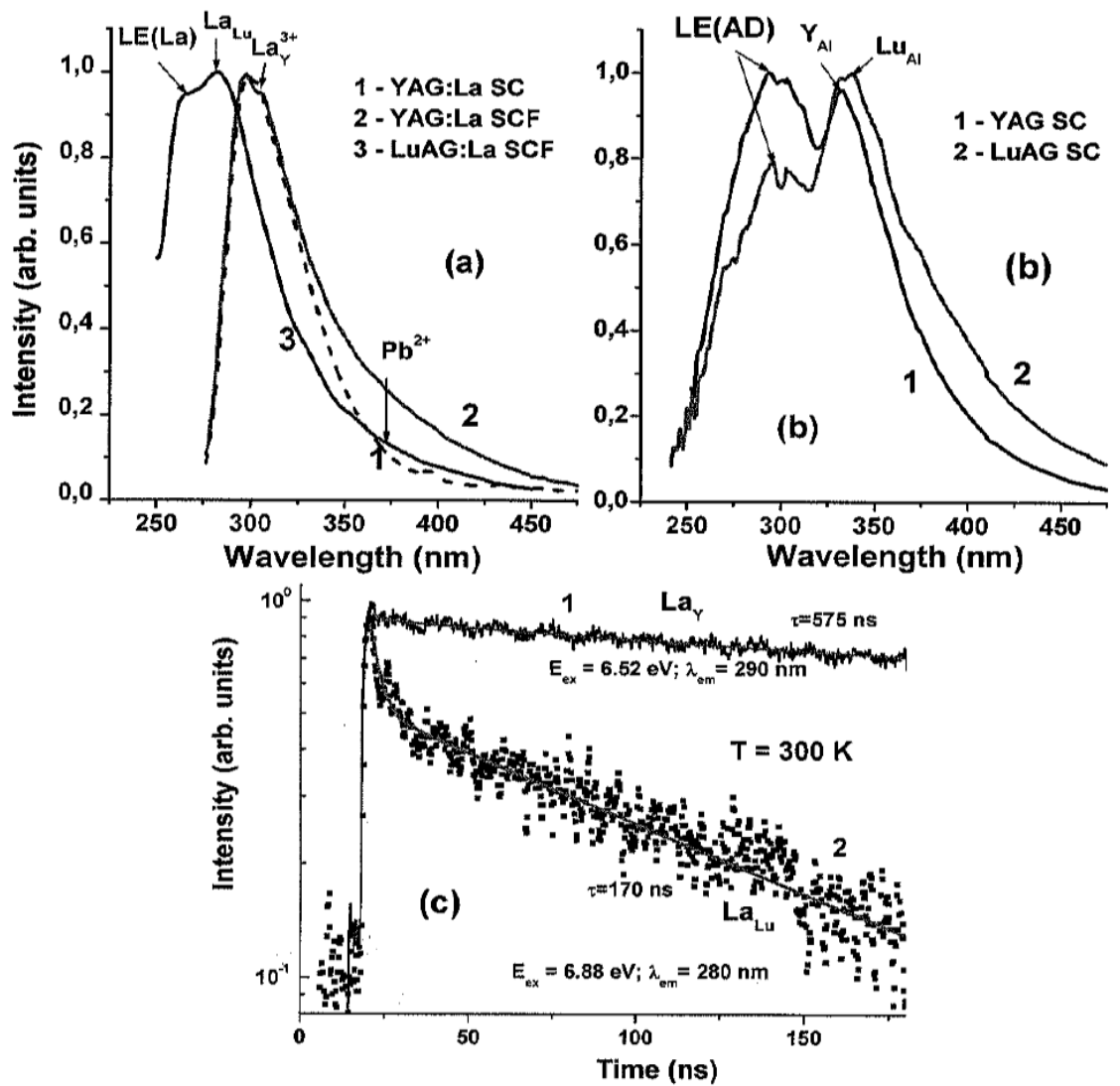

Figure 3.(a)-CL spectra of YAG:La $S C(1)$, YAG:La $S C F(2)$ and LuAG:La $S C F(3)$ at 300K; (b)CL spectra of undoped YAG (1) and LuAG (2) SC at 300K;(c)-decay kinetics of luminescence of $\mathrm{La}_{\mathrm{Y}}$ (1) and $\mathrm{La}_{\mathrm{Lu}}$ (2) centers at 290 and $285 \mathrm{~nm}$ in YAG:La and LuAG:La $S C F$ at $300 \mathrm{~K}$ under excitation by SR at 6.52 and $6.88 \mathrm{eV}$, respectively. 
The decay kinetics of luminescence of $\mathrm{La}_{\mathrm{Y}}$ and $\mathrm{La}_{\mathrm{Lu}}$ centers in YAG:La and LuAG:La SCF, under excitation in the exciton range with an energy of 6.52 and $6.88 \mathrm{eV}$, respectively, is shown in Fig.3c. The decay times of main component of $\mathrm{La}_{\mathrm{Y}}$ and $\mathrm{La}_{\mathrm{Lu}}$ centers luminescence are 560 and $170 \mathrm{~ns}$, respectively.

The LY of YAG:La and LuAG:La $S C F$ and $S C$ scintillators is not so much influenced by $\mathrm{Pb}^{2+}$ flux impurity but strongly depend on the La content in garnet host. As can be seen from Table 1, the LY of YAG:La and LuAG:La $S C F$ scintillators with La content of 0.04-0.05 at.\% is by 2-3 times lower in comparison with YAG:La (0.085at.\%) SC. Also the LY of YAG:La and LuAG:La SCF is significantly (by 2-4 times) lower than that of Sc-doped YLuAG and LuAG SCF. Such a low LY of La-doped SCF is mainly caused by very low (0.005) segregation coefficient of $\mathrm{La}^{3+}$ ions at the crystallization of YAG:La and LuAG:La $S C F$ in comparison with that (0.14) for YAG:La $S C$ analogues [21]. As a result, the rather small (0.04-0.045 at.\%) concentration of $\mathrm{La}^{3+}$ ions can be achieved in LPE-grown YAG:La and LuAG:La $S C F$ (Table 1) even at large (above 8 mole \%) content of $\mathrm{La}_{2} \mathrm{O}_{2}$ dopant in MS in comparison with an optimum value of $0.4-1.85$ at.\% for Sc-doped $S C F$ analogues of these garnets.

\subsection{Sc-doped garnets}

In contrast to $\mathrm{La}^{3+}$ ions, $\mathrm{Sc}^{3+}$ isoelectronic impurity in YAG and LuAG host has relatively high (0.8-0.55 and $0.2-0.4$, respectively) segregation coefficients $[21,22]$. This allows readily achieving the optimum values of Sc doping for both $S C$ and $S C F$ of these garnets in range $0.4-2.4$ at.\% at which the highest LY scintillators are observed (Table 1). The incorporation of $\mathrm{Sc}^{3+}$ ions in YAG and LuAG SC and SCF at total scandium content $\mathrm{x}<0.3$ formula units (f.u) results in the $\mathrm{Sc}^{3+}$ ions localization both in the dodecahedral \{c\}- and octahedral (a)-sites in ratio of about 40:60\% [27] with formation $\mathrm{Sc}_{\mathrm{Y}, \mathrm{Lu}}$ and $\mathrm{Sc}_{\mathrm{Al}}$ centers, respectively. At higher content the $\mathrm{Sc}^{3+}$ ions occupy predominantly the (a)-sites of garnet lattice (insert in Fig.4) [27]. At the same time, the relation between the $\mathrm{Sc}_{\mathrm{Y}, \mathrm{Lu}}$ and $\mathrm{Sc}_{\mathrm{Al}}$ centers in $\mathrm{YAG}$ and $\mathrm{LuAG}$ host can be changed by substitution of the $\{c\}$ - and (a) - sites of garnet lattice by other co-dopants with smaller or larger dimensions. Specifically, due to partial substitution of ${ }^{\mathrm{Y} 3+}$ cations by the $\mathrm{Lu}^{3+}$ ions, or $\mathrm{Al}^{3+}$ cations by the $\mathrm{Ga}^{3+}$ ions, the content of $\mathrm{Sc}_{\mathrm{Y}, \mathrm{Lu}}$ center in $(\mathrm{YLu})_{3} \mathrm{Al}_{5} \mathrm{O}_{12}$ and $(\mathrm{YLu})_{3} \mathrm{Al}_{5} \mathrm{GaO}_{12} S C F$ can strongly decrease up to $7-8 \%$ (Table 1$)$.

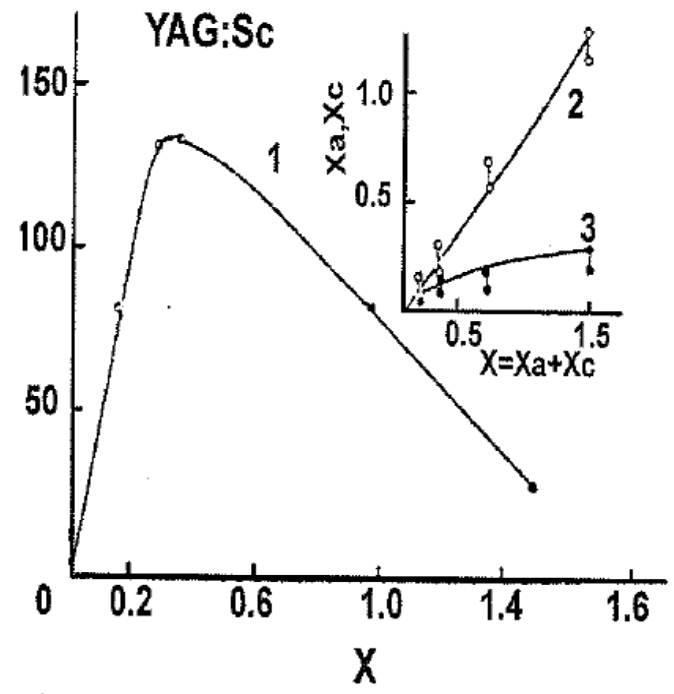

Figure 4. Dependence of integral intensity of CL (1) and concentration of $\mathrm{Sc}_{\mathrm{Al}}$ (2) and $\mathrm{Sc}_{\mathrm{Y}}(3)$ centers on total scandium content in YAG:Sc SCF.

Thus, in Sc-doped garnets the formation of two types of emission centers $\left(\mathrm{Sc}_{\mathrm{Y}, \mathrm{Lu}}\right.$ and $\left.\mathrm{Sc}_{\mathrm{Al}}\right)$ takes place which can contribute to the intensive UV luminescence of these compounds and compete in the processes of energy transfer $[27,28]$. Specifically, above mentioned distribution of $\mathrm{Sc}^{3+}$ ions over the $\{c\}-$ and (a) sites explains the complex dependence of the positions of the maximum emission bands of YAG:Sc and LuAG:Sc $S C F$ on the Sc content (Fig.4). At relatively small (x=0.05-0.15 f.u.) Sc concentration, the 
emission of $\mathrm{Sc}_{\mathrm{Y}}$ and $\mathrm{Sc}_{\mathrm{Lu}}$ centers in the bands at 313 and $290 \mathrm{~nm}$, respectively, dominates in the luminescence of YAG:Sc and LuAG:Sc SCF (Fig.5, a and b, curve 1). The bands at 353 and $335 \mathrm{~nm}$, related to the emission of $\mathrm{Sc}_{\mathrm{Al}}$ centers in YAG and $\mathrm{LuAG} S C F$, respectively, become dominant at larger $(\mathrm{x}=0.15-0.4$ f.u.) scandium concentration (Fig.5a and 5b, curve 2) which correlate with substantial increase of the LY of these $S C F$ (Fig.4, Table 1). Maximum of the LY of YAG:Sc and LuAG:Sc $S C F$ is reached at $\mathrm{x}=0.3-0.4$ f.u. (Fig.4). At highest $\mathrm{Sc}$ content the concentration quenching of $\mathrm{Sc}^{3+}$ related centers occurs.

The luminescence decay kinetics of the $\mathrm{Sc}_{\mathrm{Y}, \mathrm{Lu}}$ and $\mathrm{Sc}_{\mathrm{Al}}$ centers at $300 \mathrm{~K}$ is shown in Fig. $5 \mathrm{c}$ on example of LuAG:Sc $S C F$. Under excitation with energy of $6.88 \mathrm{eV}$ in exciton range the main components of the $\mathrm{Sc}_{\mathrm{Lu}}$ center luminescence in LuAG:Sc decay with a time of $245 \mathrm{~ns}$ (Fig.6, curve 1). The decay time of the dominant component of the $\mathrm{Sc}_{\mathrm{Al}}$ center luminescence at $300 \mathrm{~K}$ (Fig.5c, curve 2) is equal to $390 \mathrm{~ns}$.

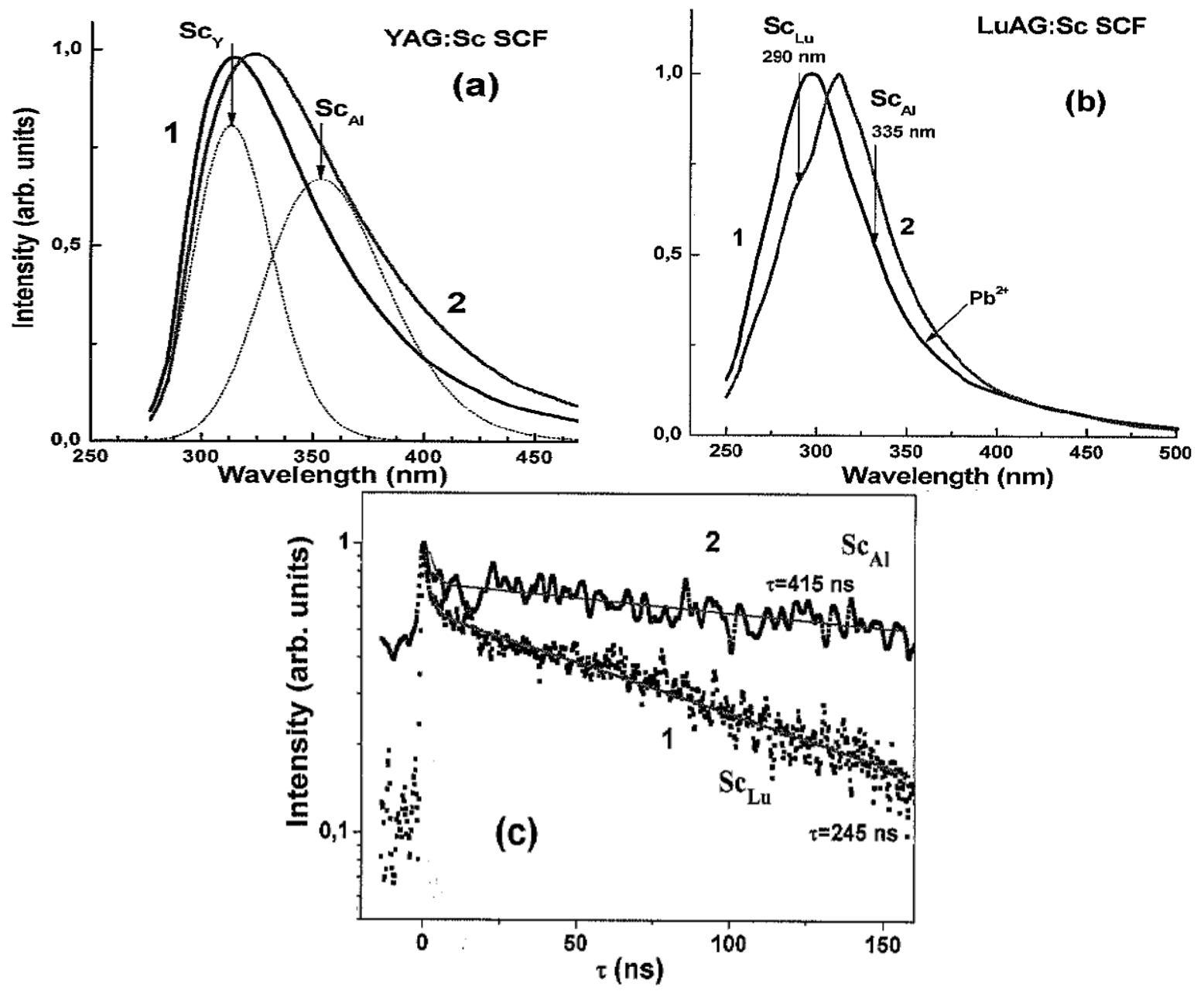

Figure $5 \mathrm{CL}$ spectra of YAG:Sc (a) and LuAG:Sc (b) $S C F$ with different Sc content at $300 \mathrm{~K}$. The content of $\mathrm{Sc}_{2} \mathrm{O}_{3}$ oxide in MS was 4.6 and 6.7 mole \% (curves 1) and 10.4 and 9.8 mole \% (curves 2), respectively. The decomposition of spectrum 2 in Fig.5a is given by the dashed lines. (c)-decay kinetics of the luminescence of $\mathrm{Sc}_{\mathrm{Lu}}$ centers at $280 \mathrm{~nm}$ (1) and $\mathrm{Sc}_{\mathrm{Al}}$ centers at $335 \mathrm{~nm}$ (2) in LuAG:Sc $S C F$ under excitation by SR with an energy of $6.88 \mathrm{ev}$ at $300 \mathrm{~K}$. 
The LY of YAG:Sc and LuAG:Sc SCF and SC scintillators is strongly depend on the total Sc content and distribution of $\mathrm{Sc}^{3+}$ dopant over the $\{c\}-$ and (a)-positions in garnet host. Specifically, the concentration of $\mathrm{Sc}_{\mathrm{Y}, \mathrm{Lu}}$ and $\mathrm{Sc}_{\mathrm{Al}}$ centers in YAG $S C F$ can be significantly changed by substitution of the $\{c\}$ - and (a)-sites of garnet lattice by $\mathrm{Lu}^{3+}$ and $\mathrm{Ga}^{3+}$ ions with smaller or larger ionic radii, respectively, than that in $\mathrm{Y}^{3+}$ and $\mathrm{Al}^{3+}$ cations. Such substitution is strongly reflected on the LY of $S C F$ scintillators. Specifically, the $\mathrm{Lu}^{3+}$ co-doping leads to increasing the LY of YAG:Sc $S C F$, whereas the $\mathrm{Ga}^{3+}$ co-doping decrease of the LY of these scintillators (Table 1). As can be seen from Table 1, the LY of (YLu)AG:Sc and LuAG:Sc SCF scintillators at the optimal $\mathrm{Sc}^{3+}$ content 0.4-0.6 f.u. is comparable with their $S C$ analogues and reaches values about 50\% of YAP:Ce and (LuY)AP:Ce standard crystal. This result shows that influence of $\mathrm{Pb}^{2+}$ dopant on the UV luminescence of $\mathrm{Sc}^{3+}$ - based centers is not so much significant as that on the luminescence of $\mathrm{Ce}^{3+}$ ions in $S C F$ of perovskites and the luminescence of $\operatorname{Pr}^{3+}$ ions in $S C F$ of garnets. It is most important that this allows to use PbO-based flux for producing $S C F$ scintillators with high LY emitting in UV range.

\section{X-ray excited luminescence spectra of SCF}

The emission spectra in 300-750 nm range of the tested LuAG:Pr/YAG, LuAG:La/YAG, LuAG:Sc/YAG and LuAP:Ce/YAP epitaxial structures with the SCF thickness of $0.8,1.7,5.0$ and $2.3 \mu \mathrm{m}$, respectively, under X-rays excitation in the direction perpendicular to $S C F$ surface, were measured with Oriel 77233 grating $(12001 / \mathrm{mm}$, blazed at $500 \mathrm{~nm})$ monochromator and Hamamatsu R4632 PMT assembly. The Xrays were operated with a $\mathrm{Cu}$ anode $(25 \mathrm{kV}, 40 \mathrm{~mA})$ and a $25 \mu \mathrm{m}$ copper filter for selection of the dominant $8 \mathrm{keV}$ line of copper for preferable excitation of $S C F$ scintillators. At the same time, the partial excitation of YAG and YAP substrates by the $8 \mathrm{keV} X$-ray is also expected due to low $(1.7-8 \mu \mathrm{m})$ thickness of $S C F$. All spectra were corrected for the grating wavelength response and the photomultiplier quantum efficiency. The results are presented in Fig.6.

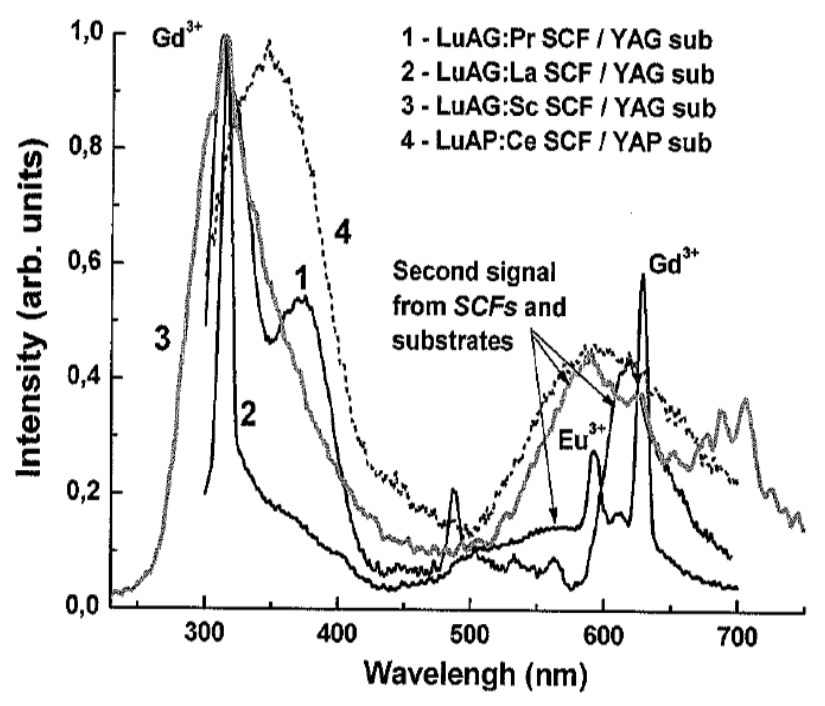

Figure 6. X-ray excited $\left(\mathrm{Cu}_{\mathrm{K} \alpha}\right)$ luminescence spectra of LuAG:Pr/YAG (1), LuAG:La/YAG (2), LuAG:Sc/YAG (3) and LuAP:Ce/YAP (4) epitaxial structures at 300K.

The X-rays excited emission spectra of LuAG:Pr/YAG, LuAG:Sc/YAG and LuAP:Ce/YAG epitaxial structures in UV range (Fig.6, curves 2 and 3) with a $S C F$ thickness of 8,5 and $2.3 \mu \mathrm{m}$, respectively, are very close to the CL spectra of their $S C F$ components (Fig.1,curve 1, Fig.2, curve 1 and Fig.3b, curve 2,respectively). At the same time, the X-rays excited emission spectra of LuAG:La/YAG epitaxial structure in UV range due to small $(1.7 \mu \mathrm{m}) S C F$ thickness present superposition of the luminescence of LuAG:La $S C F$ and YAG substrate (Fig.2, curves 2 and 3, respectively). It is necessary to note that apart from the visible emission of $\mathrm{Pr}^{3+}$ and $\mathrm{Pb}^{2+}$ ions, all epitaxial structures also reemit the part of UV light in 
the visible range (Fig.6, curves 1-4). Specifically, the sharp line bands peaked at 592, 610 and $627 \mathrm{~nm}$ in the emissions spectra of LuAG:La/YAG epitaxial structure are caused by $\mathrm{Eu}^{3+}$ ions emission and the second order of the UV emission of $\mathrm{Gd}^{3+}$ ions as trace impurities in YAG substrate. Therefore, for detection of X-ray image only in UV light, the use of a band-pass filter is strongly required, in order to cut the visible emission of scintillators.

We also estimate the conversion efficiency of the tested $S C F$ scintillators into the UV and visible ranges under X-ray excitation. The conversion efficiency is measured with an imaging system equipped with microscope objective $4 \mathrm{x}$ and CCD camera. The X-rays from copper anode, operated at $20 \mathrm{kV}, 50 \mathrm{~mA}$, were additionally separated by $25 \mu \mathrm{m}$ copper filter for receiving $8 \mathrm{keV}$ line of copper. The $S C F$ are exposed for $30 \mathrm{~s}$ and an average value of the intensity is taken on the final image. The image is corrected from detection system response to wavelength and $S C F$ thickness (X-ray absorption). All the results are compared to the conversion efficiency of the reference YAG:Ce $S C F$ scintillator. The characteristics of tested $S C F$ samples under X-ray excitation are summarized in Table 2.

Table 2 Characteristics of LuAG:Sc/YAG, LuAG:La/YAG, LuAG:Pr/YAG and LuAP:Ce/YAP epitaxialstructures under excitatiom by $8 \mathrm{keV} \mathrm{X}$-ray $(\mathrm{CuK} \alpha)$ excitation. Conversion efficiency of LuAG:La/YAG structure was measured without correction on the part of UV emission below 320 $\mathrm{nm}$, which was cut by the objective used.

\begin{tabular}{|c|c|c|c|c|}
\hline $\boldsymbol{S} \boldsymbol{C} \boldsymbol{F}$ scintillators & LuAG:La & LuAG:Sc & LuAG:Pr & LuAP:Ce \\
\hline Thickness, $\boldsymbol{\mu m}$ & 1.7 & 5.0 & 8 & 2.3 \\
\hline Main emission lines (nm) & 280,315 & 313.5 & 315,375 & 360 \\
\hline $\begin{array}{c}\text { Conversion light yield, } \% \\
\text { with respect to YAG:Ce } S C F\end{array}$ & $95 \%(\lambda>320 \mathrm{~nm})$ & & $100 \%(\lambda>320 \mathrm{~nm})$ & $20 \%$ \\
\hline $\begin{array}{c}\text { Afterglow @20ms } \\
\text { (2s exposure to X-rays) }\end{array}$ & $0.05 \%$ & & $0.29 \%$ & $0.14 \%$ \\
\hline $\begin{array}{c}\text { Afterglow @1000ms } \\
\text { (2s exposure to X-rays) }\end{array}$ & $0.001 \%$ & & $0.007 \%$ & $0.07 \%$ \\
\hline
\end{tabular}

\section{Afterglow}

The afterglow (delayed luminescence) is measured after X-rays excitation (Mo-anode) with an exposure time of $2 \mathrm{~s}$ (typical exposure time at ESRF is 0.1-10 s). The setup is made of a PMT2020Q and a SR400 gated photon counter (Stanford Research Instrument) working in the counting mode. The time resolution of the setup is $4 \mathrm{~ms}$. The results of measurements of afterglow of LuAG:La, LuAG:Pr and LuAG:Ce SCF scintillators in comparison with recently developed [5,6] LuAG:Eu and YAG:Ce $S C F$ are presented in Fig.7 and Table 2.

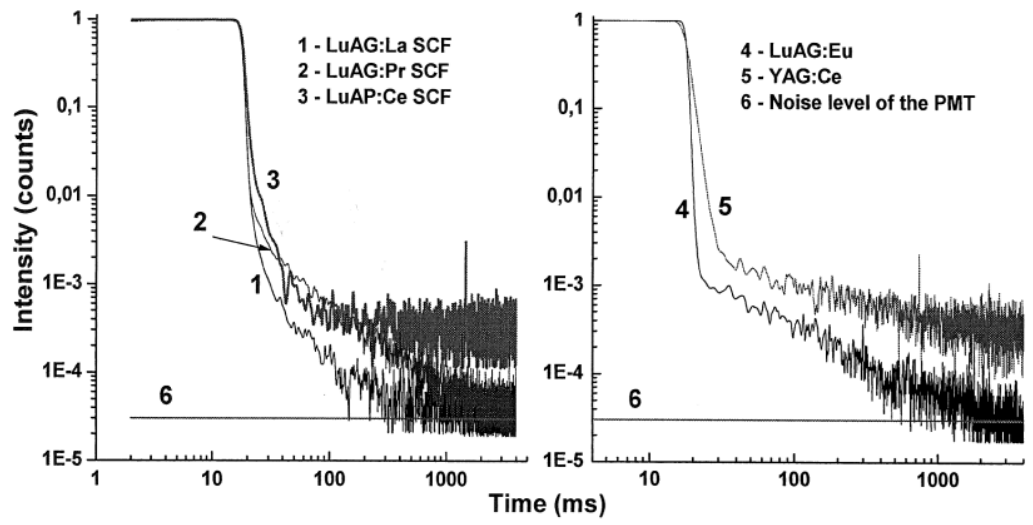

Figure 7. Afterglow of LuAG:La(1),LuAG:Pr(3) and LuAP:Ce $S C F$ scintillators in comparison with recently developed [5,6]LuAG:Eu and YAG:Ce $S C F$ scintillators following a 2s X-ray pulse exposition 
As can be seen from Fig.7, the LuAG:La and LuAG:Pr SCF scintillators shows three decay decades in the 12 and $44 \mathrm{~ms}$ time intervals and four decay decades in the 30 and $100 \mathrm{~ms}$ time intervals, respectively (curves 1 and 2). The LuAP:Ce CF scintillators shows at least 3 decay decades in the $30 \mathrm{~ms}$ time interval. For comparison, recently developed $[5,6] \mathrm{LuAG}$ :Eu and YAG:Ce $S C F$ shows three decay decades in the 5 and $55 \mathrm{~ms}$ time intervals, respectively (Fig.7, curve 4 and 5). At the same time, four decay decades for LuAG:Eu $S C F$ was obtained in the significantly largest $(384 \mathrm{~ms})$ time intervals. Unfortunately, the dynamic of the measurement does not allow to obtain the temporal response from LuAP:Ce and YAG:Ce $S C F$ samples behind 4 decades (see Fig.7, curve 3 and 5, respectively).

\section{Visualisation of X-Ray images with UV - emitting SCF scintillators}

\subsection{Flat field X-rays images}

Flat field images of the surface of tested LuAG:La, LuAG:Pr and LuAG:Ce $S C F$ scintillators were obtained using no-filtered X-ray excitation ( $\mathrm{Cu}$ anode operated at $25 \mathrm{keV}, 45 \mathrm{~mA}$ ). The Sensicam (PO) CCD camera was used as a recording device. The objective magnification was 4x. For LuAG:Pr and LuAG:La SCF only a part of their emission spectra contributes to the images because using the glass objective cuts the emission with the wavelength below $320 \mathrm{~nm}$. The results are presented in Fig.8.

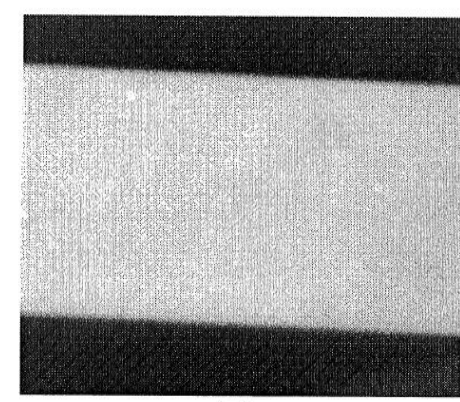

(a)

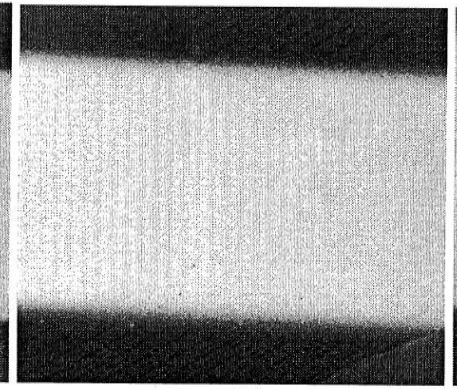

(b)

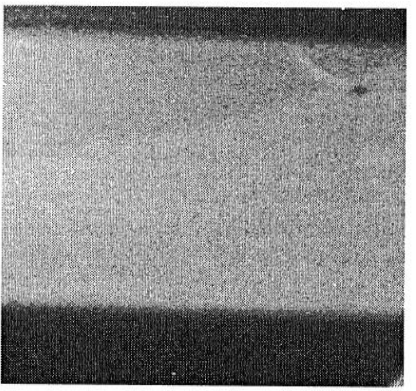

(c)

Figure 8. Flat-field image of LuAG:La (a), LuAG:Pr (b) and LuAP:Ce (c) $S C F$. Some defects on the surface of the $S C F$ scintillators can be seen

\subsection{Imaging in UV light}

We also tested the LuAG:Pr and LuAG:La $S C F$ scintillators at ESFR for visualization of image of X-ray radiated standard objects (resolution target) in the UV light. Our experimental system included the UV objective 15x, UV mirror, bandpass filter peaking at $320 \mathrm{~nm}$ and Sensicam QE CCE camera (from PCO). We could acquire images in the time less than $5 \mathrm{~s}$ with under excitation by X-ray quanta with an energy of $20 \mathrm{keV}$ and a flux of $2 \cdot 10^{10}$ photons/sec both using the total emission spectrum (UV + visible) of LuAG:Pr or LuAG:La SCF scintillators (Fig.9a) or narrow part of the UV emission bands around $320 \mathrm{~nm}$ (Fig.9b).

The first image of resolution target was obtained with a spatial resolution of about $1.5 \mu \mathrm{m}$ using only of the UV part of light of LuAG:La SCF scintillators (Fig.9b). The image resolution is comparable with quality of the image obtained with using total spectrum of LuAG:La and LuAG:Pr SCF (Fig.9a). These first results of testing are really encouraging. The UV emission of LuAG:La and LuAG:Pr SCF scintillators is efficient enough to be used for detection of the UV light following X-ray to UV conversion. That can be an interesting aspect for improving the resolution of high - resolution imaging detectors used in SR applications.

Nevertheless, we believe that the resolution of image in the UV light, presented in Fig.9b, can be significantly improved in future. The main problem of decreasing the resolution of the detector is connected with the large part of the UV light, emitting from the substrate, which then reemits in the visible range (Fig.6). Therefore, the ratio of the UV light coming from SCF and substrate must be substantially increased for the studied compounds by the way of increase of the total LY of SCF scintillators. We plan to test other UV-emitting $S C F$ scintillators with relatively higher LY, specifically LuAG:Sc, LuYAG:Sc $S C F$ (Table 1) as well as LuAG:Bi $S C F$ [16] for visualization of X-ray image in the UV light. We also expect that a increase of the LY of LuAG:Pr and especially LuAP:Ce SCF scintillators can be achieved by means of using of lead-free fluxes for their crystallization by LPE method. Namely, 
we obtain the first good results on YAP:Ce $S C F$ crystallization from $\mathrm{BaO}-\mathrm{B}_{2} \mathrm{O}_{3}-\mathrm{BaF}_{2}$ flux [24] with comparable LY in comparison with the same SCF grown from the PbO-based flux with strongly exponential decay kinetic of $\mathrm{Ce}^{+3}$ emission (Table 1).

\section{Conclusion}

Development of three types of UV -emitting single crystalline film $(S C F)$ scintillators grown by liquid phase epitaxy methods (LPE) is considered in this work:

1) $\mathrm{Ce}^{3+}$ doped $S C F$ of Y-Lu-Al perovskites, where the fast and intensive f-d luminescence of $\mathrm{Ce}^{3+}$ ions with a decay time of 16-17 ns occurs in the 360-370 nm range;

2) $\mathrm{Pr}^{3+}$ doped $S C F$ of Y-Lu-Al garnets, where the fast and intensive f-d luminescence of $\mathrm{Pr}^{3+}$ ions in the 300-400 nm range with decay time 13-17 ns is realized;

3) $S C F$ of Y-Lu-Al-garnet compounds doped with $\mathrm{La}^{3+}$ or $\mathrm{Sc}^{3+}$ isoelectronic impurities emitting in the 290-400 nm range due to formation of $\mathrm{La}_{\mathrm{Y}, \mathrm{Lu}}$ or $\mathrm{Sc}_{\mathrm{Y}, \mathrm{Lu}}$ and $\mathrm{Sc}_{\mathrm{Al}}$ emission centers with the decay time of the luminescence in several hundred ns range.

(a)
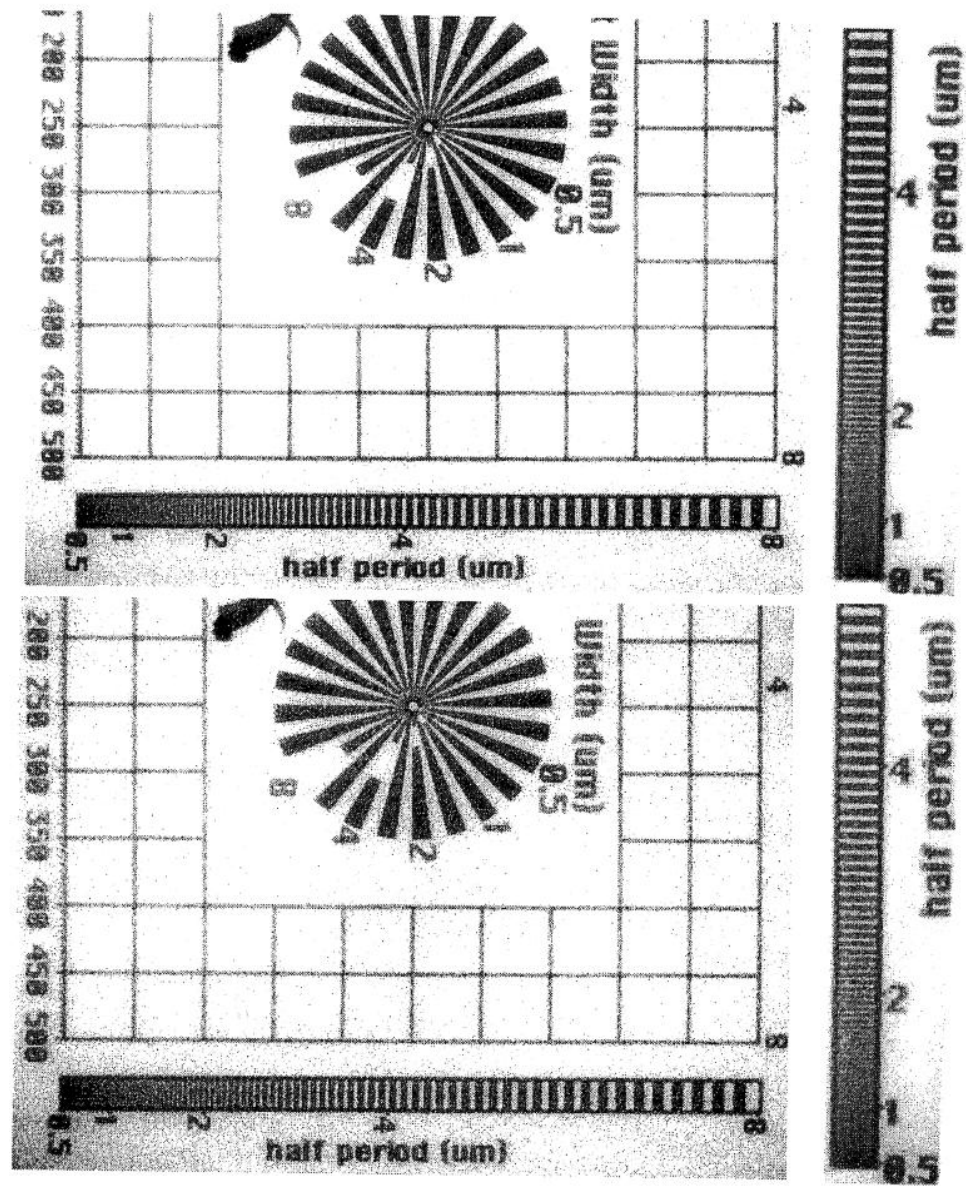

Figure 9. Images of resolution target obtained using the total spectrum (UV+visible) (a) and only of UV part of emission (b) of LuAG:La $S C F$ scintillator

We have tested several novel UV-emitting LuAG:Pr, LuAG:La and LuAP:Ce SCF scintillators for visualization of X-ray images at ESFR. The UV emission of the LuAG:Sc,LuAG:La and LuAG:Pr SCFs is efficient enough for conversion of X-ray to UV light. This can be an interesting alternative to increase the resolution of imaging detectors used in synchrotron radiation applications. The first image with a 
spatial resolution of about $1.5 \mu \mathrm{m}$ of resolution target was obtained using only of the UV part of light of the LuAG:La SCF scintillators.

The main problem in the development of these types of scintillators by LPE method from the traditional $\mathrm{PbO}-\mathrm{B}_{2} \mathrm{O}_{3}$ flux is connected with the significantly larger influence of $\mathrm{Pb}^{2+}$ flux dopant on the UV luminescence of $\mathrm{Pr}^{3+}$ ions in $S C F$ of garnets and $\mathrm{Ce}^{3+}$ ions in $S C F$ of perovskites than in the case of recently developed YAG:Ce and LuAG:Ce $S C F$ scintillators emitting in the visible range. This is the main reason for lower (by 2-3 times) LY of Pr - doped YAG and LuAG SCF and significantly lower (by 4-7.6 times) LY of Ce-doped YAP and LuAP SCF scintillators in comparison with their single crystals analogues. At the same time, the influence of $\mathrm{Pb}^{2+}$ dopant on the UV luminescence of $\mathrm{La}^{3+}$ and especially $\mathrm{Sc}^{3+}$ - based centers is not so significant than on the luminescence of $\mathrm{Ce}^{3+}$ and $\mathrm{Pr}^{3+}$ ions in $S C F$ of perovskites and garnets. This allows using PbO-base flux for producing $S C F$ scintillators emitting in the UV range with high $L Y$.

The possible ways for improvement of figure-of-merit of UV-emitting $S C F$ scintillators are discussed. Specifically, future development of UV scintillators based on $\mathrm{Ce}^{3+}$-doped $S C F$ of perovskites, and $\mathrm{Pr}^{3+}, \mathrm{La}^{3+}$ and $\mathrm{Sc}^{3+}$ doped $S C F$ of garnets strongly demands the use of alternative lead-free fluxes for their crystallization. In this work, we present the set of results related to using the $\mathrm{BaO}-\mathrm{B}_{2} \mathrm{O}_{3}-\mathrm{BaF}_{2}$ flux for crystallization of UV -emitting YAP:Ce $S C F$ perovskites. We show, that the advantageous properties of YAP:Ce $S C F$ scintillators, grown from the $\mathrm{BaO}$ - based flux, with respect to those grown from the traditional $\mathrm{PbO}$ - based flux, are connected with removing the additional channels of dissipation of excitation energy on the luminescence and trapping charge carriers at $\mathrm{Pb}$ - based centers.

\section{Acknowledgement}

This research was supported by Czech Science Foundation (project no. 202/08/0893) and Ministry of Education and Science of Ukraine (projects No DZ/296-2008 and no SL-28F).

\section{References}

[1] Robertson J M, van Tol M V 1984 Cathodoluminescent garnet layers Thin Solid Films 114(1-2) $220-40$

[2] Zorenko Yu V, Novosad S S, Pashkovskii M V, Lyskovich A B, Savitskii V G, Batenchuk M M, Malyutenkov P S, Patsagan N I, Nazar I V and Gorbenko V I 1990 Epitaxial structures of garnets as scintillators detectors of ionizing radiation Journal of Applied Spectroscopy 52(6) 645-49

[3] Ferrand B, Chambaz M and Couchaud M 1999 Liquide phase epitaxy. A versalite technique for the development of miniature optical components in single crystal dielectric media. Optical Materials 11 101-14

[4] Globus M, Grinyov B, Ratner M, Tarasov V, Lyubinskiy V, Vyadi Y, Ananenko A, Zorenko Y, Gorbenko V and Konstankevych I 2004 New type of scintillation detectors for biological, medical and radiation monitoring applications. IEEE Transact. on Nucl.Sci. 51(3) 1297-303

[5] Koch A, Raven C,Spanne P and Snigirev A 1998 X-ray imaging with sub-micrometer resolution employing transparent luminescent screens. J.Opt.Soc.Am. A 15 1940-51

[6] Koch A, Peyrin F, Heurtier P, Chambaz B, Ferrand B, Ludwig W and Couchaud M 1999 An X -ray camera for computed microtomography of biological samples with micrometer resolution using $\mathrm{Lu}_{3} \mathrm{Al}_{5} \mathrm{O}_{12}$ and $\mathrm{Y}_{3} \mathrm{Al}_{3} \mathrm{O}_{12}$ scintilators 1999 Proc.SPIE 3659 170-9

[7] Martin T and Koch A 2006 Recent development in X-ray imaging with micrometer spatial resolution Journal of Synchrotron Radiation 13 180-94

[8] Zorenko Yu, Batenchuk M, Pashkovsky M, Konstankevych I, Gorbenko V, Yurchushyn P, Martynova V and Duzyj T 1998 Single crystalline film sensors for cathode-ray tubes: possibilities of application, peculiarities and light parameters, Proc.SPIE 3359 261-64

[9] Hrytskiv Z D, Zorenko Y, Gorbenko V,Peden A D and Shkliarskyi V I 2007 Single crystalline film screens for cathode-ray tubes: New life of television scanning optical microscopy. Radiation Measurements 42 (4-5) 933-36 
[10] Zorenko Yu V, Konstankevich I V, Gorbenko V I and Yurchishin P I 2002 Journal of Applied Spectroscopy 69 769-76

[11] Zorenko Yu, Gorbenko V, Konstankevich I, Grinev B and Globus M 2002 Scintillation properties of $\mathrm{Lu}_{3} \mathrm{Al}_{5} \mathrm{O}_{12}$ :Ce single crystalline films NIM A486 309-14

[12] Zorenko Yu, Gorbenko V, Konstankevych I, Voloshinovskii A, Stryganyuk G, Mikhailin V, Kolobanov V and Spassky D 2005 Single - crystalline films of Ce-doped YAG and LuAG phosphors: advantages over bulk crystals analogues Journal of Luminescence 114 (4) 85-94

[13] Zorenko Y, Gorbenko V,Mihokova E, Nikl M,Nejezchled K,Vedda A,Kolobanov V and Spassky D Single crystalline film sicintilators based on Ce-and Pr-doped aluminium garnets 2007 Radiation Measurements 42 521-27

[14] Nikl M, Mihokova E, Pejchal J, Vedda A, Zorenko Yu and Nejezchled K 2005 The antisite $\mathrm{Lu}_{\mathrm{Al}}$ defect - related trap in $\mathrm{Lu}_{3} \mathrm{Al}_{5} \mathrm{O}_{12}$ :Ce single crystal Phys.Stat.Sol. b $242 \mathrm{R} 119-21$

[15] Prsusa P,Cechak T,Mares J A, Nikl M, Zorenko Yu V, Gorbenko V I, Tous J and Blazek K 2008 The $\alpha$-particle excited scintillation response of the liquid phase epitaxy grown LuAG:Ce thin films Applied Physics Letters 2(1) 1-3

[16] Zorenko Yu, Voloshinovskii A,Savchyn V, Vozniak T,Nikl M, Nejezchled K, Mikhailin V, Kolobanov V and Spassky D 2007 Exciton and antisite defect - related luminescence in $\mathrm{Lu}_{3} \mathrm{Al}_{5} \mathrm{O}_{12}$ and $\mathrm{Y}_{3} \mathrm{Al}_{5} \mathrm{O}_{12}$ garnets Phys.Stat. Sol. b 244 2180-89

[17] Nikl M, Pejchal J, Yoshikawa A, Fukuda T, Krasnikov A, Vedda A, and Nejezchleb K $2006 \operatorname{Pr}^{3+}$ doped novel single crystal scintillators ed.Getkin A and Grinyov B SCINT 2005 Proc.of the 8 Inter.Conf. on inorganic scintillators and their use in science and industrial applications, Alishta, Crimea Ukraine, Kharkiv 89-94

[18] Zorenko Y and Gorbenko V 2007 Growth peculiarities of the $\mathrm{R}_{3} \mathrm{Al}_{5} \mathrm{O}_{12}(\mathrm{R}=\mathrm{Lu}, \mathrm{Yb}, \mathrm{Tb}, \mathrm{Eu}-\mathrm{Y})$ single crystalline film phosphors by Liquid Phase Epitaxy Radiation Measurements 42 907-10

[19] Zorenko Y, Gorbenko V, Konstankevych I, Voznjak T, Savchyn V, Nikl M, Mares J A, Nejezchleb K, Mikhailin V, Kolobanov V and Spassky D 2007 Peculiarities of luminescence and scintillation properties of YAP:Ce and LuPA:Ce single crystals and single crystalline films Radiation Measurements 42 528-32

[20] Zorenko Y, Gorbenko V, Batentschuk M and Winnacker A 2009 Growth and luminescent properties of single crystalline films of $\mathrm{RAlO}_{3}(\mathrm{R}=\mathrm{Lu}, \mathrm{Lu}-\mathrm{Y}, \mathrm{Y}, \mathrm{Tb})$ perovskites Phys.Stat.Sol. accepted

[21] Zorenko Yu, Konstankevych I, Gorbenko V and Zorenko T 2002 Growth and characteristics of crystallophosphors on the base of single crystalline films of LuAG and YAG garnets 2002 Molecular Physics Reports 36 127-32

[22] Zorenko Yu, Gorbenko V and Konstankevych I 2003 Peculiarities of growth of phosphors based on the single crystalline films of garnets by liquid phase epitaxy method Surface 5 C83-90

[23] Babin V,Gorbenko V,Makhov A,Mares J A, Nikl M, Zazubovich S and Zorenko Yu 2007 Luminescence characteristics of $\mathrm{Pb}^{2}+\rightarrow \mathrm{Ce}^{3+}$ energy transfer processes Journal of Luminescence 127(2) 384-90

[24] Zorenko Y, Gorbenko V, Savchyn V, VoznyakT, Nikl M, Mares J A, Beitlerova A and Kucerkova R 2009 The luminescent and scintillation properties of YAP and YAP:Ce single crystalline films grown by liquid phase epitaxy from BaO-based flux Phys.Stat.Sol. a submitted;

Globus M and Grinyov B 2000 Non - inorganic scintillators (Akta, Kharkiv)

[25] Babin V, Bichevin V, Gorbenko V, Makhov A,Mhokova E,Nikl M, Vedda A, Zuzubovich S and Zorenko Yu 2009 Luminescence of dimmer lead centers in aluminium perovskites and garnets Phys.Stat.Sol. B 246(6) 1318-26

[26] Gorbenko V,Krasnikov A, Nikl M, Zuzubovich S and Zorenko Yu 2009 Luminescence characteristics of LuAG:Pr and YAG:Pr crystalline films Optical Materials 31 1805-07

[27] Valbis J A, Volzhenskaja L G,Dubov Yu G, Zorenko Yu V, Nazar I V and Patszagan N I 1987 Luminescence centers in single crystalline compounds of yttrium-aluminium garnet doped by scandium isoelectronic impurity Optics and Spectroscopy 63 1058-63 
[28] Zorenko $\mathrm{Yu} \mathrm{V} 2006$ Luminescence of $\mathrm{La}^{3+}$ and $\mathrm{Sc}^{3+}$ isoelectronic impurities in $\mathrm{Lu}_{3} \mathrm{Al}_{5} \mathrm{O}_{12}$ single crystalline films Optics and Spectroscopy 100 572-80

[29] Zorenko Y, Mares J A, Kucerkova R, Gorbenko V, Savchyn V,Voznyak T, Nikl M,Beitlerova A and Jurek K 2009 Optical, luminescence and scintillation characteristics of the Bi-doped LuAG and YAG single crystalline films J.Phys.D Appl Phys. 427 